\title{
A NOVEL HABITAT-BASED APPROACH TO PREDICT IMPACTS OF MARINE PROTECTED AREAS ON FISHERS
}

João B. Teixeira ${ }^{1,2}$, Rodrigo L. Moura ${ }^{1,2, ~ *}$, Morena Mills ${ }^{3}$, Carissa Klein ${ }^{4}$, Christopher J. Brown ${ }^{5}$, Vanessa M. Adams ${ }^{3}$, Hedley Grantham ${ }^{6,3}$, Matthew Watts ${ }^{3}$, Deborah Faria ${ }^{2}$, Gilberto M. AmadoFilho $^{7}$, Alex C. Bastos $^{8}$, Reinaldo Lourival ${ }^{9}$, Hugh P. Possingham ${ }^{3}$

1- Instituto de Biologia and SAGE/COPPE, Universidade Federal do Rio de Janeiro. Rio de Janeiro RJ 21941-599 Brazil. Corresponding author: moura.uesc@gmail.com

2- Programa de Pós-Graduação em Ecologia e Conservação da Biodiversidade, Universidade Estadual de Santa Cruz. Ilhéus BA 45650-000 Brazil.

3- The School of Biological Sciences, The University of Queensland, St. Lucia, Qld 4072, Australia

4- The School of Geography, Planning, and Environmental Management, The University of Queensland, St. Lucia, Qld 4072, Australia

5- Australian Rivers Institute, Griffith University, Nathan, QLD 4111, Australia

6- Conservation Science and Solutions, Wildlife Conservation Society, 750 9th St., NW, Suite 525, Washington, DC 20001, USA

7- Instituto de Pesquisas Jardim Botânico do Rio de Janeiro. Rio de Janeiro RJ 22460-030 Brazil

8- Departamento de Oceanografia, Universidade Federal do Espírito Santo. Vitória 29090-600 ES Brazil.

9- Universidade Federal de Mato Grosso do Sul. Campo Grande, 79070-900 MS Brazil.

Keywords: Opportunity cost; Abrolhos Bank; Small-scale fisheries, Conservation planning

This article has been accepted for publication and undergone full peer review but has not been through the copyediting, typesetting, pagination and proofreading process, which may lead to differences between this version and the Version of Record. Please cite this article as doi: 10.1111/cobi.12974.

This article is protected by copyright. All rights reserved. 
Running head: Marine Protected Areas and fishers

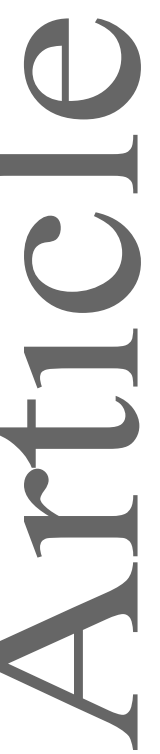

\section{Abstract}

While marine protected areas (MPAs) can simultaneously contribute to biodiversity conservation and fisheries management, the global network is biased towards particular ecosystem types, as it was largely established in an ad hoc fashion. The optimization of trade-offs between biodiversity benefits and socio-economic values increases implementation success and minimizes enforcement costs in the long run, but is often neglected in marine spatial planning (MSP). Although the acquisition of spatially explicit socioeconomic data is often perceived as a costly/secondary step in MSP, it is critical to account for lost opportunities by people whose activities will be restricted, especially fishers. Here we present an easily-reproducible habitat-based approach to estimate the spatial distribution of opportunity cost to fishers in data poor regions, assuming that the most accessible areas have higher values and their designation as no-take zones represents increased loss of fishing opportunities. Our method requires only habitat and bathymetric maps, a list of target species, the location of ports, and the relative importance for each port and/or vessel/gear type. The potential distribution of fishing resources is estimated from bathymetric ranges and benthic habitat distribution, while the relative importance of the different resources is estimated for each port, considering total catches $(\mathrm{kg})$, revenues and/or stakeholder perception. Finally, the model can combine different cost layers to produce a comprehensive cost layer, and also allows for the evaluation of tradeoffs. The development of FishCake was based on data from a contentious conservation-planning arena (Abrolhos Bank, Brazil) in which attempts to expand MPA coverage failed due to fishers' resistance. The opportunity cost approach that we introduce herein allows for the incorporation of economic interests of different stakeholders and evaluation of tradeoffs among different stakeholder groups. The novel approach can be directly used to support conservation planning, in Abrolhos and elsewhere, and is expected to facilitate community consultation.

\section{INTRODUCTION}

Given the overall degraded state of marine biodiversity and global overfishing (Pauly \& Zeller, 2016), marine spatial planning (MSP) is becoming one of the most important tools for marine conservation and management (Sala et al. 2002; Wood et al. 2008). MSP consists of a public process of analyzing and allocating human activities, including marine protected areas (MPAs), in order to achieve 
ecological, economic and social objectives specified through a social and political process (Douvere, 2008; Douvere et al. 2007; Stelzenmüller et al. 2013).

The global targets from the Convention of Biological Diversity (CBD) known as the Aichi targets are fuelling declarations of new MPAs globally (Toropova et al. 2010). By 2020, CBD signatories aim to increase MPA coverage from the current $\sim 2 \%$ up to $10 \%$ of the ocean (CBD 2010). While MPAs can contribute simultaneously to biodiversity conservation and fisheries management (Alcala \& Russ 2006; Fox et al. 2012), the existing global MPA network is biased towards particular geographies and ecosystems (Klein et al. 2015) and was established with low stakeholder participation (Devillers et al. 2014; Mills et al. 2015). This context, combined with poor management, results in most MPAs failing to deliver on their biological and socioeconomic objectives (Edgar et al. 2014).

The process of configuring MPA networks is increasingly being supported by decision support software designed to identify priority areas for different types of management (Watts et al. 2009). This systematic approach for MPA design uses data representing both the features of interest and the opportunities and limitations for implementation (Teh et al. 2012). A key component of spatial prioritization is minimizing economic impacts to stakeholders, especially those with an active role in extracting fishing resources. In most developing countries, recreational interests in seascapes dominated by small-scale fisheries are limited, and therefore were not considered herein. Assessing spatial variation in the relative cost of management is a critical component of MSP, not only for optimizing the always-scarce conservation funds, but also because it reduces social conflict by minimizing overlaps between competing activities (Ban \& Klein 2009; Deas et al. 2014; Weeks et al. 2010b). Socioeconomic costs typically included in MSP are management (e.g. implementation, ongoing enforcement costs) and opportunity (forgone economic opportunities) costs (Ban \& Klein 2009). Although long-term non-extractive values may exceed lost opportunities of extractive uses (Sanchirico et al. 2002), loss of fishing grounds is one of the most important opportunity costs to be considered when planning for MPAs (Ban \& Klein 2009). The inclusion of data obtained from stakeholders is particularly important in the context of developing countries, where data are limited and social acceptance is a critical dimension in MPA management (Adams et al. 2010; Ban et al. 2009; Johannes 1998). The balance between minimizing opportunity costs to fishers while creating no-take and other restrictive zoning types can increase their support and compliance (Weeks et al. 2010b).

This article is protected by copyright. All rights reserved. 
Estimates of opportunity costs to fishers can be derived from different data types and sources. Catchand-effort data can represent fisheries revenues (Klein et al. 2010; Wood \& Dragicevic 2007), but spatial gaps in such data are frequent and can result in unexploited areas being wrongly mapped as fished and vice-versa (Adams et al. 2011; Stewart \& Possingham 2005). Multivariate stochastic bioeconomic models may overcome such gaps (Ban et al. 2009; Grafton et al. 2004), but demand high-resolution catch-and-effort historical data that are rarely available, especially for small-scale fisheries (Richardson et al. 2006). Density of boats or fishers' numbers can be used as regional surrogates (Ban et al. 2009; Green et al. 2009; Sala et al. 2002), but distribution of fleet data within fishing grounds is elusive, just as fleet mobility beyond seasonal and diel patterns (Sala et al. 2002; Weeks et al. 2010b). Finally, fishers may directly provide relevant cost information (Scholz et al. 2004; Ban \& Klein 2009; Teixeira et al. 2013; Yates et al. 2013), but consultation processes often fail to represent the heterogeneous social landscape. Biases are stronger when fishing activity is genderand age- structured, or when small-scale fisheries coexist with recreational and industrial fisheries, escalating urbanization, and industrial activities. In such situations, outspoken groups with the largest rewards or losses tend to be disproportionally influential (Smith et al. 2010).

While methods to estimate opportunity costs in terrestrial environments are well developed (e.g. probability of land conversion and agricultural rents) (Naidoo \& Adamowicz 2006; Naidoo \& Iwamura 2007), similar methods for seascapes dominated by small-scale artisanal fisheries are limited (but see Adams et al. 2011). Here, we present an easily-reproducible approach to estimate the opportunity cost to fishers, based on simple catch data and benthic habitat maps that are relatively easy to compile in data poor seascapes.

\section{METHODS}

\section{Study area and datasets}

The Abrolhos Bank is a $200 \mathrm{~km}$ wide portion of the tropical Brazilian continental shelf, with about $50,000 \mathrm{~km}^{2}$, located between the States of Bahia and Espírito Santo. It represents the most biodiverse marine area in the South Atlantic (Amado-Filho et al. 2012; Moura et al. 2013) and is recognized as a global "Ecologically or Biologically Significant Area" (https://www.cbd.int/ebsa/). Nearly 300 
species of fish and 20 species of reef-building corals are recorded in its benthic mosaic of rhodolith beds, reefs, soft bottom, mangroves and vegetated sandbanks. Despite limited spatial coverage, MPAs are the main fisheries management tool in Abrolhos (Moura et al. 2013): 1.7\% of the shelf is covered by one no-take MPA (Abrolhos National Park, $880 \mathrm{~km}^{2}$ ) and $3.7 \%$ is covered by two co-managed MPAs that allow extractive uses by traditional people (Corumbau Extractive Reserve, $895 \mathrm{~km}^{2}$ and Cassurubá Extractive Reserve, 1,000 km²). A large (3,400 km²) multiple-use MPA under Bahia State jurisdiction has had no enforcement or management since its declaration in 1993 (Fig. 1a-d). With a few exceptions (e.g. shrimp and lobster seasonal closures), there are virtually no other forms of fisheries management (e.g. minimum/maximum sizes). Here, the entire planning region was divided into a $1 \mathrm{~km}^{2}$ grid, from the estuaries and beaches to the shelf edge (200 $\mathrm{m}$ isobath), resulting in 50,762 planning units.

Abrolhos' small-scale fisheries account for more than half of Northeastern Brazil's landings (Freitas et al. 2011). Catch (total landings: kg.year ${ }^{-1}$ ) and first commercialization price (in Brazilian Reais $\mathrm{R} \$$ ) were obtained from three projects funded by the former Ministério da Pesca e Aquicultura in 2011 (since then fisheries monitoring was halted countrywide and the ministry was extinguished; see Pinheiro et al. 2015). The first dataset (ES) was obtained by the Universidade Federal do Espírito Santo and covers the main ports in Espírito Santo State (Silva \& Soares 2013). The second dataset (BA) was obtained by the non-governmental Organization (NGO) ECOMAR and covers the ports of Prado, Alcobaça, Caravelas, Nova Viçosa and Mucuri, the most important landing spots in southern Bahia (Freitas et al. 2011). The third dataset (ER) was obtained by NGO Conservation International and covers the ports within the Corumbau and Cassurubá Extractive Reserves, also in Southern Bahia (unpublished). These three datasets were treated as different groups of ports, in which different vessel types operate (gear/target species and boat size obtained from the Ministério da Pesca e Aquicultura database $<$ http://sinpesq.mpa.gov.br/rgp $>$ ).

\section{Opportunity costs}

In order to estimate opportunity costs of fishers' displacement by no-take reserves we introduce a simple approach, the "FishCake" model (Fig. 2), which is also provided as a user-friendly R-script (R Development Core Team, 2017) (Supporting Information). The model requires input data that is 
relatively easy to acquire: habitat and bathymetric maps, list of target species (with habitat and depth associations compiled from the literature), distance between ports and planning units, and the relative importance of each resource for each port and/or vessel/gear type (e.g. catches, revenues and/or stakeholder perception) (Fig. 2). The primary outputs include (I) data layers with the (potential) distribution of resources, (III) relative importance of each resource for each port and/or vessel/gear type, and (III) a distance function (ports to fishing grounds). The final result is a heterogeneous layer of opportunity costs for fishers. This novel approach is based on three main assumptions. First, areas with more co-occurrences of target species have higher opportunity costs, as fishers can target multiple species (e.g. Aswani 1998). Second, the habitat of the most important resources (i.e. those with higher yields or price) is associated with higher opportunity costs. Finally, areas nearer to ports are cheaper to fish and therefore have higher opportunity costs (e.g. Adams et al. 2011). The core components used in FishCake (habitat maps, relative importance of resource, distance function) are detailed below.

The three datasets that we used are typical of data-poor fisheries in tropical developing countries, and included 142 fish taxa (Supporting Information), four lobster species (Panulirus argus, P. echinatus, P. laevicauda and Scyllarides brasiliensis), two octopus genera (Octopus and Eledone), two species and one genus of crabs (Goniopsis cruentata, Ucides cordatus and Callinectes spp.), and five shrimp species (Litopenaeus schimitti, Farfantepenaeus brasiliensis, F. paulensis, F. subtilis, Xiphopenaeus kroyeri). Some taxa were lumped as resources $(\mathrm{n}=75)$ (e.g. parrotfishes -6 spp., groupers -4 spp., shrimps - 5 spp.). Resources' distributions were mapped based on habitat- and depth-associations (estuaries, unconsolidated bottom, reefs, and rhodolith beds) obtained from field guides (e.g. Lessa \& Nóbrega 2000) and FishBase (Froese \& Pauly 2013).

Catch data $\left(\mathrm{kg} \mathrm{year}^{-1}\right)$ and first commercialization prices were used to inform the importance of each resource among the three groups of ports (BA, ES and ER). Total catch of these groups was divided by the catch of each resource and multiplied by its price. The resulting values were standardized from 0 to 1 in order to represent the relative importance of resource (RI). In the few absences of catch and/or price data, RI was obtained through stakeholder consultation, through a ranking process.

This article is protected by copyright. All rights reserved. 
Opportunity costs in fishing grounds nearer to ports are higher, and the size and shape of the planning region also implies a nonlinear cost decrease as distance from ports increases. Therefore, we calculated a distance function (DF) from each group of ports using two parameters: the rate of cost decline $(\alpha)$ and a minimum cost multiplier $(\beta)$, and is given by:

$$
D F_{i, p}=\left(e^{(d \times \alpha)}+\beta\right)-\left(e^{(d \times \alpha)} \beta\right)
$$

Where $\mathrm{DF}_{\mathrm{i}, \mathrm{p}}$ is the distance from a planning unit $\mathrm{i}$ and a port $\mathrm{p} ; \alpha$ is the rate of cost decline with distance; $\beta$ is the minimum cost multiplier.

The opportunity cost for fishers (OC) is given by:

$$
O C_{i, p}=\left(\sum_{j}^{n} \frac{a_{i, j}}{A_{j}} R_{j}\right) D F_{i, p}
$$

Where $\mathrm{OC}_{\mathrm{i}, \mathrm{p}}$ is the opportunity cost for the fishes from group of ports $\mathrm{p} ; \mathrm{a}_{\mathrm{i}, \mathrm{j}}$ is the area of resource $\mathrm{j}$ in planning unit $i ; A_{j}$ is the total distribution area of the resource $j ; R_{j}$ is the relative importance of resource $\mathrm{j}$; and $\mathrm{DF}_{\mathrm{i} . \mathrm{p}}$ takes values in eq. (1).

We made separate calculations of opportunity costs for each of the three group of ports, conservatively setting $\alpha$ at -0.000009 and $\beta$ at 0.1 . Vessel type (shrimp trawling and vessels using passive gears) was used to further refine opportunity cost layers. Colinearity among cost layers was assessed using pairs plot, with relationships illustrated as LOESS smoothers and corresponding Pearson's correlation coefficients. For each group of ports we evaluated the correlation of cost layers. Highly uncorrelated costs $(<90 \%)$ were grouped, resulting in a comprehensive 'full cost' layer. Conversely, cost layers for shrimp trawling of ER and BA were identical, resulting in a total of six cost layers retained for the development of conservation scenarios. All cost layers were scaled from 0 to 1 .

This article is protected by copyright. All rights reserved. 


\section{Conservation scenarios}

We used Marxan (Ball et al. 2009) to explore tradeoffs in six conservation scenarios based on different cost layers produced with FishCake. Marxan is a decision support software used for conservation planning globally. It uses simulated annealing to identify areas that, if protected, achieve a set of biodiversity targets for a minimum cost (Ball et al. 2009). We ran Marxan for six different scenarios, which varied in terms of what opportunity cost data was used (S1-S6, including one for each of the five port/vessel groups and a "full cost" scenario). Each scenario targeted full protection against fisheries in $30 \%$ of each benthic habitat (estuary, unconsolidated bottom, shallow reefs, mesophotic reefs, rhodolith beds, and continental slope) (Fig. 1b). We set Marxan to find 100 'near optimal' solutions for each scenario. The boundary length modifier (BLM), a parameter that controls fragmentation of selected areas, was set to 0 in order to isolate the effect of costs on solutions to the problem. The species penalty factor (SPF) was calibrated for each scenario following Ardron et al. (2010), in order to keep shortfalls consistent and to make results comparable.

Relationships among Marxan solutions were evaluated with hierarchical clusters and nMDS biplots based on a Jaccard resemblance matrix, following Harris et al. (2014). Analyses were performed with R (R Development Core Team, 2017) using the hclust, metaMDS and vegdist functions of the Vegan package (Oksanen et al. 2013). In addition, an envfit analysis was performed to determine which explanatory variables are best correlated across the nMDS ordinations. Explanatory variables included the following parameters (continuous vectors) of each Marxan solution: number of selected planning units; score; cost; minimum proportion of target met (MPM); penalty; and missing value. Significantly correlated variables $(a=0.05)$ were plotted as axes on the main bidimensional nMDS diagram. We also evaluated how much each best solution (smallest objective function score over 100 runs) costs for each scenario, in total and for each group of stakeholders (Adams et al. 2011). Databases, shapefiles and R script are provided as Supporting Information.

\section{RESULTS}

The FishCake model revealed a heterogeneous mosaic of opportunity costs within the planning region, as the opportunity costs of fishers' displacement by reserves differ among groups of ports (ES, 
BA, ER). The three groups of ports encompass distinct vessel sizes and gears (Fig. 3a, b), target distinct resources, and present highly different catches (ES $\sim 6,590$ ton.year $^{-1}, \mathrm{BA} \sim 850$ ton.year $^{-1}$ and ER $\sim 120$ ton.year $^{-1}$ ) (Fig. 3c).

The registered regional fishing fleet by port includes 961 gillnet vessels (55\% ES, $21 \% \mathrm{BA}, 24 \% \mathrm{ER}$ ), 884 trawling vessels (37\% ES, 46\% BA, 18\% ER), 739 longline vessels (80\% ES, 10\% BA, 10\% ER), 675 line vessels (27\% ES, 35\% BA, 38\% ER), and 146 diving vessels (27\% ES, 48\% BA, 25\% ER). Despite such diversity of fishing fleets/gears, scenarios using all vessel types and resources resulted in highly correlated opportunity cost layers (e.g. ES vs $\mathrm{ER}=0.76$; $\mathrm{BA} v s \mathrm{ER}=0.68$; $\mathrm{p}<0.0001$ ). The cost correlation between ES and BA ports was also significant, but weaker (ES vs $\mathrm{BA}=0.37 ; \mathrm{p}<0.0001$ ), regardless of the variables used to calculate the importance factor and the distance function.

Our habitat-based approach also highlights the effects of each opportunity cost for different types of fisheries on Marxan solutions (Fig. 4). Despite the overall high correlation between cost layers (Fig. $5 \mathrm{a}$ ), the multivariate analysis of Marxan outputs showed significant differences among conservation solutions for the six scenarios (Fig 5b, c). Shrimp is the main resource from ES and ER groups. Due to regional bias towards shrimp trawling, we contrasted conservation scenarios with and without shrimp yields. The BA and ER trawling scenarios were identical due to shared shrimp fishing grounds, and therefore S5 represents both groups. Scenarios considering only coastal trawling vessels tended to select offshore planning units for conservation. For instance, the S5 solution (BA/ER Trawling) had a higher concentration of selected planning units in the south of the planning region, contrasting with other solutions (e.g. S4 using ES trawling cost). The "full cost" scenario (S6) reflects a selection pattern primarily driven by higher-value fisheries (e.g. shrimp trawling) and resulted in the smallest global opportunity cost (S6) (Fig. 5d).

\section{DISCUSSION}

In order to deliver more equitable outcomes and therefore improve the robustness and resilience of conservation decisions, all stakeholder groups should have a say in MSP (Klein et al. 2008). Fishers, due to their wide presence, dependency and role in contemporary marine ecosystems (Jackson et al. 2001), represent a crucial stakeholder group to be considered, especially in the coastal zones of developing countries where alternative livelihoods are not an option in the foreseeable future. 
Opportunity cost models using catch and effort data provide accurate estimates of potential fishing losses from no-take zoning of MPAs (Adams et al. 2011), but they depend on high resolution data that is most often unavailable (Deas et al. 2014; Richardson et al. 2006). Here, we present an alternative habitat-based approach to predict impacts to different groups of fishers under the data-limited contexts typical of developing countries.

Data on catch distribution of small-scale fisheries is generally scarce and its collection can be costly and time-consuming (Adams et al. 2011; Deas et al. 2014; Leopold et al. 2014; Weeks et al. 2010b). Even when catch data is available, it tends to be largely underestimated, with significant variations between small scale, commercial and subsistence fisheries (Pauly \& Zeller 2016). Under such circumstances, socio-economic data may represent alternative surrogates to represent opportunity costs (Ban \& Klein 2009; Deas et al. 2014; Weeks et al. 2010b). However, crude generalizations based on surrogates that are arbitrarily exchanged among sites may lead to inefficient solutions, and the improvement of surrogates is a major need of MSP (Christensen et al. 2009; Deas et al. 2014). The substitution of coarse-resolution data (e.g. population census, number of fishers or boats) by fine resolution and empirical fishing effort distribution improves the reliability and accuracy of the solutions (Richardson et al. 2006; Weeks et al. 2010b; Adams et al. 2011; Deas et al. 2014). However, the use of this kind of data is still associated to spatial-temporal biases and high costs associated to data collection. Our approach offers an alternative for data poor regions. Although habitat maps may be costly and time-consuming to produce with standard oceanographic methods (Moura et al. 2013), they can be readily and accurately acquired from local knowledge (Teixeira et al. 2013). The algorithm is provided as a user-friendly R script to assist MSP within data poor contexts, and allows for fine-tuning the importance of species for different stakeholder groups as additional information is updated during consultation processes. FishCake can be used to address similar contexts, and more groups of ports can be easily added (see Supporting Information). The resulting maps can also be validated by stakeholders during planning, if/when opportunities are appropriately provided.

Thus, rather than focusing on assessing current extractive effort, the FishCake algorithm considers the variation in the spatial distribution of important resources (see Adams et al. 2011), but relies only on habitat maps and landing data to distinguish the relative importance of each planning unit for each stakeholder group. The resulting opportunity cost layers do not 
necessarily identify the most fished areas, but provide a useful starting point for guiding reserve design by avoiding the most accessible areas with high availability of important resources in multi-species fisheries.

\section{Assumptions and caveats}

Given limited data availability, some assumptions on fish distribution are inevitable. Our model assumes homogeneous fishing yield within a given habitat, but some level of within-habitat variation in the density of target species is always expected (Manson \& Die 2001). In addition, while demersal and reef-associated species strongly respond to depth, relief and benthic community structure, the distribution of pelagic and migratory species may be harder to infer from habitat data. Our model relies on depth and benthic habitat associations and its comprehensiveness is therefore limited.

Additionally, we assumed stability in the importance factor (IF), a parameter that distinguishes stakeholder groups. Snapshot assessment of landings and prices may fail to capture market dynamics, as it is related to fluctuations on environmental forcing (e.g. climate anomalies) and fishing techniques/technology (Adams et al. 2011; van de Geer et al. 2013), as well as on shifting demand following the decline of some resources. Redistribution of fishing effort after no-take reservation may also impact the relative importance of some resources, as fleets may respond in different ways (Cabral et al. 2017). Historical catch data, when available, can be used to provide more reliable importance ranks for the resources exploited by each stakeholder group. However, we emphasize that such data is rarely available. FishCake serves as a starting point for stakeholder consultation aiming to identify important resources with low spatial-temporal variability (Weeks et al. 2010b), a critical step for building trust among local communities that will be impacted by MSP (e.g. Moura et al. 2009).

The fishing fleets studied in Abrolhos have similar mobility capabilities (size/engine power), and we did not detect vessels with significant longer ranges. However, in contexts where some vessels are long ranging (i.e. present lower opportunity cost at distance), parameters $\alpha$ 
(rate of cost decline with distance) and $\beta$ (minimum cost multiplier) may be adjusted in the distance function (see Supporting Information for a sensitivity analysis of the distance function). Finally, we remark that artisanal fisheries in developing countries are also driven by resource availability, risk aversion and cultural identity (; Pet-Soede et al. 2001; Salas \& Gaertner 2004; van de Geer et al. 2013; Deas et al. 2014; Maire et al. 2016), and such factors remain to be explicitly considered.

\section{FishCake in a real world application}

The Abrolhos Bank Shelf is considered a priority area for marine biodiversity conservation in Brazil and harbors the country's first National Marine Park $\left(807 \mathrm{~km}^{2}\right)$. This no-take MPA was legally established in 1983 under an ad hoc design developed by government officials, allegedly aiming to compromise conservation and economic activities (Moura et al. 2003). Two other multiple-use and community co-managed MPAs were established in 2000 and 2009 (Corumbau and Cassurubá Extractive Reserves: 895 and 1,006 km², respectively), based on traditional fishers' territorial claims and ad hoc consultation by NGOs. Despite encompassing three relatively large MPAs, the regional protection network is still far from being representative in terms of habitat coverage, as it is largely estuarine/coastal (see Fig. 1 d). In 2001, the Brazilian Protected Areas Agency (ICMBio) and environmental NGOs proposed a mosaic of new no-take MPAs to expand marine protection in Abrolhos. Although Marxan was used as a decision support tool, a single homogeneous cost layer for fishers was considered. Ultimately, these MPAs were not created due to the broad rejection by local fishers, who complained about inequity and lack of transparency in the planning process. Fishers complained that the proposed MPAs did not encompass several multiple-use areas that were long being discussed with the government and, more importantly, did not account for the obvious spatial variability of the opportunity costs for fishers. For instance, the main nearshore shrimp trawling grounds were assigned to a high selection frequency to receive a no-take MPA, negatively affecting ES and ER fishers.

If the Abrolhos' MSP process is resumed by ICMBio, FishCake can be used improve its acceptance by providing heterogeneous and more comprehensive opportunity cost layers representing the different groups of ports and fisheries (e.g. Trawling and Passive Gears). In Abrolhos, the "full cost" 
scenario (Fig. 4, S6) has the minimum global opportunity cost and can be used as a starting point for achieving a more efficient MPA network design, and also to stimulate the refining of cost data trough stakeholder input. Here, although we did not aim to anticipate a specific final solution, we also suggest that MSP in Abrolhos (and elsewhere with complex seascapes and multi-gear artisanal fisheries) is addressed with multiple zoning algorithms such as Marxan with Zones, which can benefit from FishCake outputs. Cost layers are a prerequisite for robust spatial planning in which the goal is to minimize the combination costs of the reserve network, whilst meeting a set of biodiversity targets (Ball et al. 2009). However, when homogeneous opportunity cost layers are used as a shortcut in the planning process, they fail to represent all stakeholders, ultimately leading to inequitable distribution of costs, and lack of support by local communities (Deas et al. 2014).

FishCake allowed for a more explicit assessment of tradeoffs between stakeholder groups. If such a multidimensional and heterogeneous opportunity cost landscape is not considered, the resulting solutions can be very cheap for one group and extremely expensive to another. Contrasts between the "full cost" scenario and solutions that consider each stakeholder group individually are a potential starting point for receiving inputs from stakeholders, allowing for the fine-tuning of opportunity cost datasets. Opportunity cost layers obtained from FishCake can be used to assist data input in decision support systems such as Marxan and Marxan with Zones (Ball et al. 2009; Watts et al. 2009). Moreover, it can be simply employed as a tool to facilitate community consultation (Adams et al. 2011), adding an alternative approach to the development of surrogates for opportunity costs data poor regions.

\section{Acknowledgments}

We thank the fisherfolks from the Extractive Reserves of Corumbau and Cassurubá for the continued support to our fieldwork, and the Colônias dos Pescadores (Fishing Guilds) from the municipalities of Porto Seguro, Prado, Alcobaça, Caravelas, Nova Viçosa, Conceição da Barra, Linhares e Aracruz. Logistical and financial support was provided by the ICMBio, Conservation International, A Voz da Natureza, CNPq, FAPES, FAPERJ, CAPES, PELD-Abrolhos (www.abrolhos.org) and ANP/Brasoil. 


\section{LITERATURE CITED}

Adams VM, Mills M, Jupiter SD, Pressey RL. 2011. Improving social acceptability of marine protected area networks: a method for estimating opportunity costs to multiple gear types in both fished and currently unfished areas. Biological Conservation 144:350-361.

Adams VM, Pressey RL, Naidoo R. 2010. Opportunity costs: who really pays for conservation? Biological Conservation 143:439-448.

Alcala AC, Russ GR. 2006. No-take marine reserves and reef fisheries management in the Philippines: a new people power revolution. Ambio 35:245-254.

Amado-Filho GM et al. 2012. Rhodolith beds are major $\mathrm{CaCO}_{3}$ bio-factories in the tropical south west Atlantic. PLoS ONE 7:e35171.

Ardron JA, Possingham HP, Klein CJ. 2010. Marxan good practices handbook, version 2. Pacific Marine Analysis and Research Association.

Aswani S. 1998. Patterns of marine harvest effort in southwestern New Georgia, Solomon Islands. Ocean \& Coastal Management 40:207-235.

Ball IR, Possingham HP, Watts ME. 2009. Marxan and relatives: software for spatial conservation prioritization. Spatial conservation prioritisation: quantitative methods and computational tools. Oxford University Press, Oxford.

Ban NC, Hansen GJA, Jones M, Vincent ACJ. 2009. Systematic marine conservation planning in data-poor regions: socioeconomic data is essential. Marine Policy 33:794-800.

Ban NC, Klein CJ. 2009. Spatial socioeconomic data as a cost in systematic marine conservation planning. Conservation Letters 2:206-215.

Cabral RB, Gaines SD, Johnson BA, Bell TW, White C. 2017. Drivers of redistribution of fishing and non-fishing effort after the implementation of a marine protected area network. Ecol Appl 27:416-428.

CBD. 2010. Convention on biological diversity target 11, Aichi biodiversity targets. http://www.cbd.int/sp/targets/ (accessed September 2014).

Christensen V, Ferdaña Z, Steenbeek J. 2009. Spatial optimization of protected area placement incorporating ecological, social and economical criteria. Ecological Modelling 220:2583-2593.

This article is protected by copyright. All rights reserved. 
Deas M, Andréfouët S, Léopold M, Guillemot N. 2014. Modulation of habitat-based conservation plans by fishery opportunity costs: a New Caledonia case study using fine-scale catch data. PloS ONE 9:e97409.

Devillers R, Pressey RL, Grech A, Kittinger JN, Edgar GJ, Ward T, Watson R. 2014. Reinventing residual reserves in the sea: are we favouring ease of establishment over need for protection? Aquatic Conservation: Marine and Freshwater Ecosystems 25:480-504.

Douvere F. 2008. The importance of marine spatial planning in advancing ecosystem-based sea use management. Marine Policy 32:762-771.

Douvere F, Maes F, Vanhulle A, Schrijvers J. 2007. The role of marine spatial planning in sea use management: the Belgian case. Marine Policy 31:182-191.

Edgar GJ et al. 2014. Global conservation outcomes depend on marine protected areas with five key features. Nature 506:216-220.

Fox HE et al. 2012. Reexamining the science of marine protected areas: linking knowledge to action. Conservation Letters 5:1-10.

Freitas MO, Moura RL, Francini-Filho RB, Minte-Vera CV. 2011. Spawning patterns of commercially important reef fish (Lutjanidae and Serranidae) in the tropical western South Atlantic. Scientia Marina 75:135-146.

Froese R. Pauly D. 2011. FishBase. Available from www.fishbase.org (accessed July 2013).

Grafton RQ, Kompas T, Schneider V. 2004. The bioeconomics of marine reserves: a selected review with policy implications. Journal of Bioeconomics 7:161-178.

Green A et al. 2009. Designing a resilient network of marine protected areas for Kimbe Bay, Papua New Guinea. Oryx 43:488.

Harris LR, Watts ME, Nel R, Schoeman DS, Possingham HP. 2014. Using multivariate statistics to explore trade-offs among spatial planning scenarios. Journal of Applied Ecology 51:1504-1514.

ICMBio. 2011. Proposição de Unidades de Conservação na Região dos Abrolhos. Brasília-DF, pp. 27. Available from http://www.icmbio.gov.br/portal/images/stories/o-que-fazemos/ Propostas_UCs_Banco_Abrolhos_0512_novo2.pdf (accessed February 2015).

Jackson JB et al. 2001. Historical overfishing and the recent collapse of coastal ecosystems. Science 293: 629-37. 
Johannes R. 1998. The case for data-less marine resource management: examples from tropical nearshore finfisheries. Trends in Ecology \& Evolution 13:243-246.

Klein CJ, Brown CJ, Halpern BS, Segan DB, McGowan J, Beger M, Watson JE. 2015. Shortfalls in the global protected area network at representing marine biodiversity. Scientific Reports $\mathbf{5}$.

Klein CJ, Chan A, Kircher L, Cundiff AJ, Gardner N, Hrovat Y, Scholz A, Kendall BE, Airamé S. 2008. Striking a balance between biodiversity conservation and socioeconomic viability in the design of marine protected areas. Conservation Biology 22:691-700.

Klein CJ, Steinback C, Watts M, Scholz AJ, Possingham HP. 2010. Spatial marine zoning for fisheries and conservation. Frontiers in Ecology and the Environment 8:349-353.

Leopold M, Guillemot N, Rocklin D, Chen C. 2014. A framework for mapping small-scale coastal fisheries using fishers' knowledge. ICES Journal of Marine Science 71:1781-1792.

Lessa R, Nóbrega M. 2000. Programa REVIZEE/SCORE-NE-Guia de identificação de peixes marinhos da região Nordeste. Recife, UFRPE-DIMAR, 128p.

Maire E et al. 2016. How accessible are coral reefs to people? A global assessment based on travel time. Ecology Letters 19: 351-360.

Manson FJ, Die DJ. 2001. Incorporating commercial fishery information into the design of marine protected areas. Ocean \& Coastal Management 44:517-530.

Mills M, Weeks R, Pressey RL, Gleason MG, Eisma-Osorio R-L, Lombard AT, Harris JM, Killmer AB, White A, Morrison TH. 2015. Real-world progress in overcoming the challenges of adaptive spatial planning in marine protected areas. Biological Conservation 181:54-63.

Moura RL et al. 2013. Spatial patterns of benthic megahabitats and conservation planning in the Abrolhos Bank. Continental Shelf Research 70:109-117.

Moura RL, Minte-Vera CV, Curado IB, Francini-Filho RB, Rodrigues HDCL, Dutra GF, Alves DC, Souto FJB. 2009. Challenges and prospects of fisheries co-management under a marine extractive reserve framework in Northeastern Brazil. Coastal Management 37:617-632.

Naidoo R, Adamowicz WL. 2006. Modeling opportunity costs of conservation in transitional landscapes. Conservation Biology 20:490-500.

Naidoo R, Balmford A, Ferraro PJ, Polasky S, Ricketts T, Rouget M. 2006. Integrating economic costs into conservation planning. Trends in Ecology and Evolution 21:681-687.

This article is protected by copyright. All rights reserved. 
Naidoo R, Iwamura T. 2007. Global-scale mapping of economic benefits from agricultural lands: Implications for conservation priorities. Biological Conservation 140:40-49.

Oksanen J, Blanchet FG, Kindt R, Legendre P, Minchin PR, O'Hara RB, Simpson GL, Solymos P, Stevens MHH, Wagner H. 2013. Package "vegan.” Community ecology package, version 2.

Pauly D, Zeller D. 2016. Catch reconstructions reveal that global marine fisheries catches are higher than reported and declining. Nature Communications 7:10244.

Pet-Soede C, Van Densen WLT, Hiddink JG, Kuyl S, Machiels MAM. 2001. Can fishermen allocate their fishing effort in space and time on the basis of their catch rates? An example from Spermonde Archipelago, SW Sulawesi, Indonesia. Fisheries Management and Ecology 8:15-36.

Pinheiro HT, Di Dario F, Gerhardinger LC, de Melo MRS, Moura RL, Reis RE, Vieira F, Zuanon J, Rocha LA. 2015. Brazilian aquatic biodiversity in peril. Science 350:1043-4.

Richardson EA, Kaiser MJ, Edwards-Jones G, Possingham HP. 2006. Sensitivity of marine-reserve design to the spatial resolution of socioeconomic data. Conservation Biology 20:1191-1202.

Sala E, Aburto-Oropeza O, Paredes G, Parra I, Barrera JC, Dayton PK. 2002. A general model for designing networks of marine reserves. Science 298:1991-1993.

Salas S, Gaertner D. 2004. The behavioural dynamics of fishers: management implications. Fish and Fisheries 5:153-167.

Sanchirico JN, Cochran KA, Emerson PM. 2002. Marine protected areas: Economic and social implications. Resources for the Future May 2002:24.

Scholz A, Bonzon K, Fujita R, Benjamin N, Woodling N, Black P, Steinback C. 2004. Participatory socioeconomic analysis: drawing on fishermen's knowledge for marine protected area planning in California. Marine Policy 28: 335-349.

Silva MH, Soares GSS. 2013. Boletim estatístico da pesca do Espírito Santo: ano 2011.

Smith MD, Lynham J, Sanchirico JN, Wilson JA. 2010. Political economy of marine reserves:

Understanding the role of opportunity costs. Proceedings of the National Academy of Sciences 107:18300-18305.

Stelzenmüller V, Lee J, South A, Foden J, Rogers SI. 2013. Practical tools to support marine spatial planning: A review and some prototype tools. Marine Policy 38:214-227.

Stewart RR, Possingham HP. 2005. Efficiency, costs and trade-offs in marine reserve system design. Environmental Modeling \& Assessment 10:203-213.

This article is protected by copyright. All rights reserved. 
Teh LCL, Teh LSL, Pitcher TJ. 2012. A tool for site prioritisation of marine protected areas under data poor conditions. Marine Policy 36:1290-1300.

Teixeira JB, Martins AS, Pinheiro HT, Secchin NA, Moura RL, Bastos AC. 2013. Traditional ecological knowledge and the mapping of benthic marine habitats. Journal of Environmental Management 115:241-250.

Toropova C, Meliane I, Laffoley D, Matthews E, Spalding M. 2010. Global ocean protection: present status and future possibilities. IUCN.

van de Geer C, Mills M, Adams VM, Pressey RL, McPhee D. 2013. Impacts of the Moreton Bay Marine Park rezoning on commercial fishermen. Marine Policy 39:248-256.

Watts ME, Ball IR, Stewart RS, Klein CJ, Wilson K, Steinback C, Lourival R, Kircher L, Possingham HP. 2009. Marxan with Zones: Software for optimal conservation based land- and sea-use zoning. Environmental Modelling \& Software 24:1513-1521.

Weeks R, Russ GR, Bucol AA, Alcala AC. 2010. Shortcuts for marine conservation planning: the effectiveness of socioeconomic data surrogates. Biological Conservation 143:1236-1244.

Wood LJ, Dragicevic S. 2007. GIS-based multicriteria evaluation and fuzzy sets to identify priority sites for marine protection. Biodiversity and Conservation 16:2539-2558.

Wood LJ, Fish L, Laughren J, Pauly D. 2008. Assessing progress towards global marine protection targets: shortfalls in information and action. Oryx 42:340-351.

Yates KL, Schoeman DS. 2013. Spatial access priority mapping (SAPM) with fishers: a quantitative GIS method for participatory planning. PLoS ONE 8: e68424.

\section{FIGURE LEGENDS}

Figure 1. The Abrolhos Bank shelf, Brazil (inset): (a) detailed bathymetric profile; (b) benthic megahabitats; (c) potential distribution of penaeid shrimp fishing grounds (from bathymetric and benthic habitat data); (d) Fishing ports, existing MPAs and catch data for Espírito Santo State fleets (ES). 


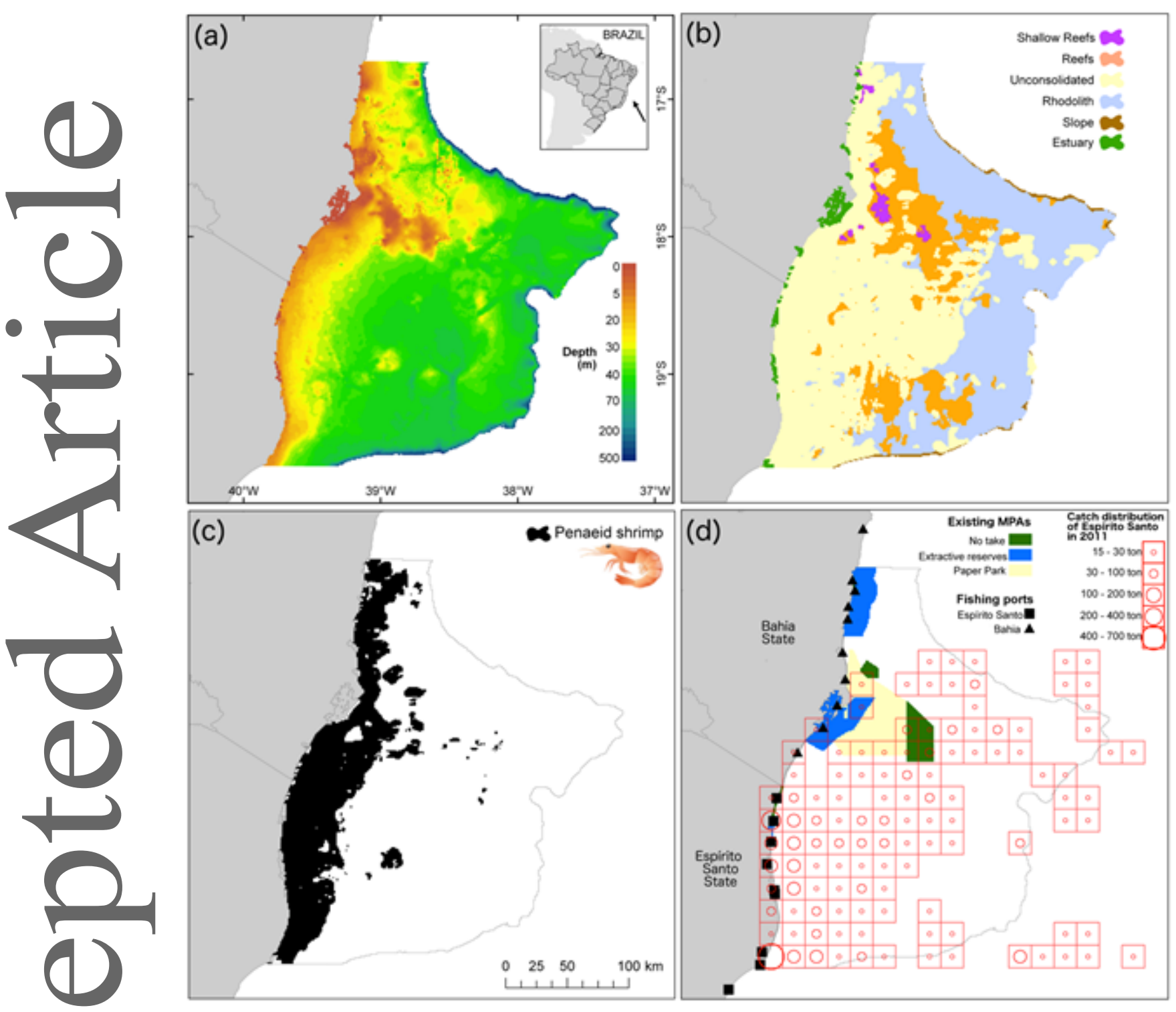

Figure 2. Conceptual model used to estimate the opportunity cost for fisheries in the Abrolhos Bank shelf (FishCake). *Not used.

This article is protected by copyright. All rights reserved. 


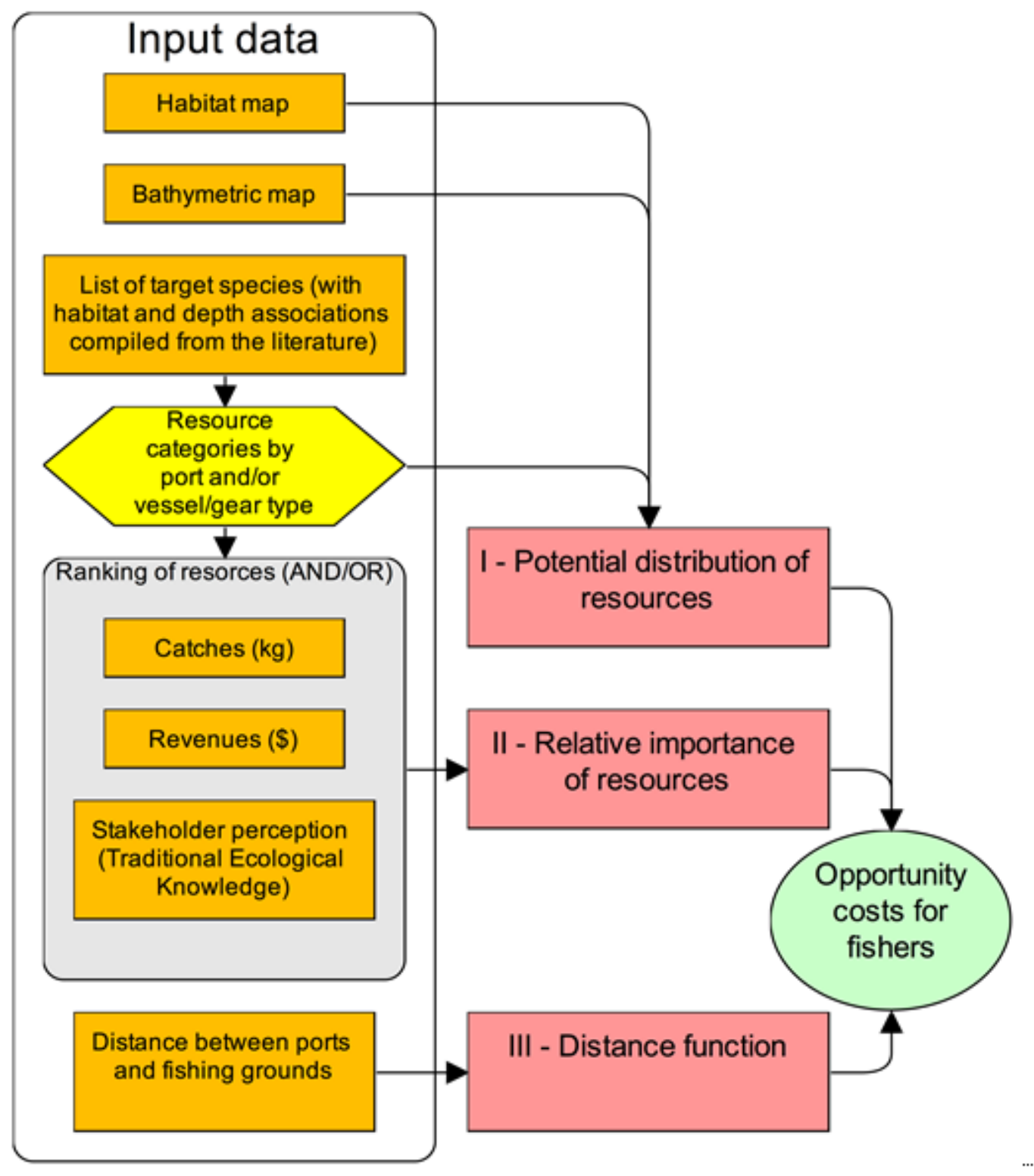

Figure 3. Characteristics of the fishing fleets that operate in the Abrolhos Bank and relative importance of the main fisheries resources landed in each Group of Ports: (a) gear types; (b) boat size; (c) landings. ES= Espírito Santo State; $\mathrm{BA}=$ Bahia State; ER= Extractive Reserves. Species represented as Resources are listed in the Supporting Information.

This article is protected by copyright. All rights reserved. 
(a)

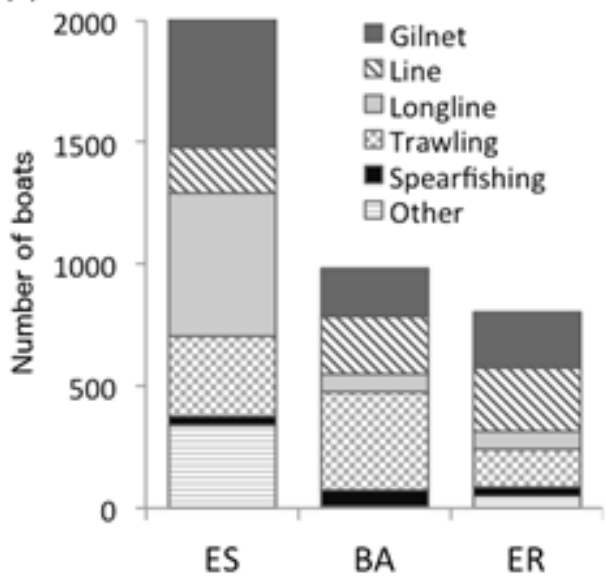

(b)

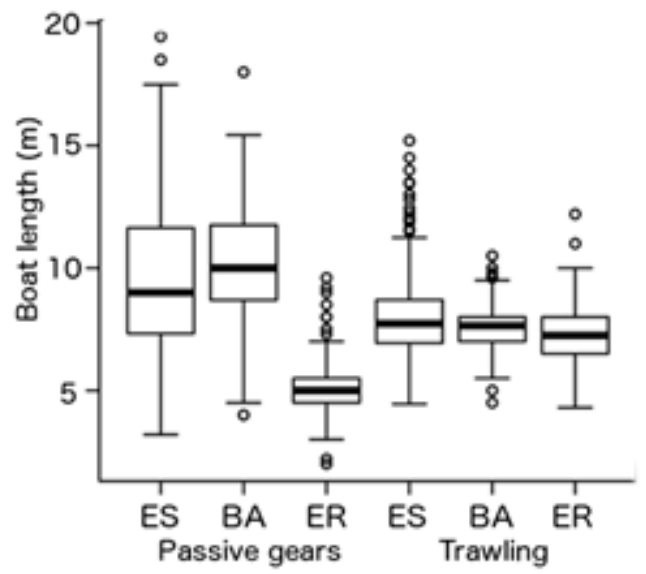

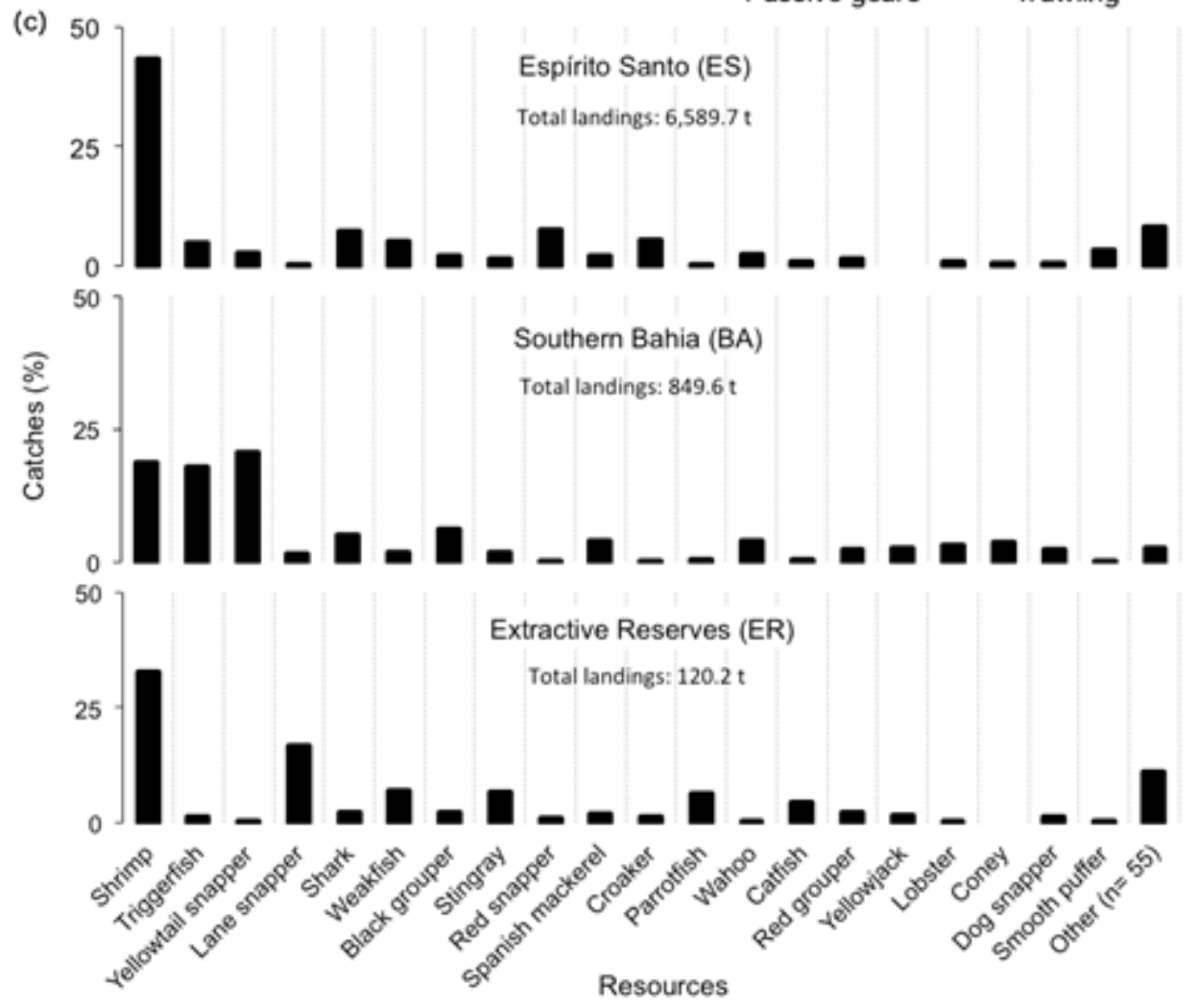

Figure 4. Spatial distribution of opportunity costs and respective Marxan selection frequencies (100 replicated runs, targets comprising $30 \%$ of each habitat) for the six planning scenarios, S1-S6 (one for each of the five ports/vessel groups, and a "full cost" scenario).

This article is protected by copyright. All rights reserved. 


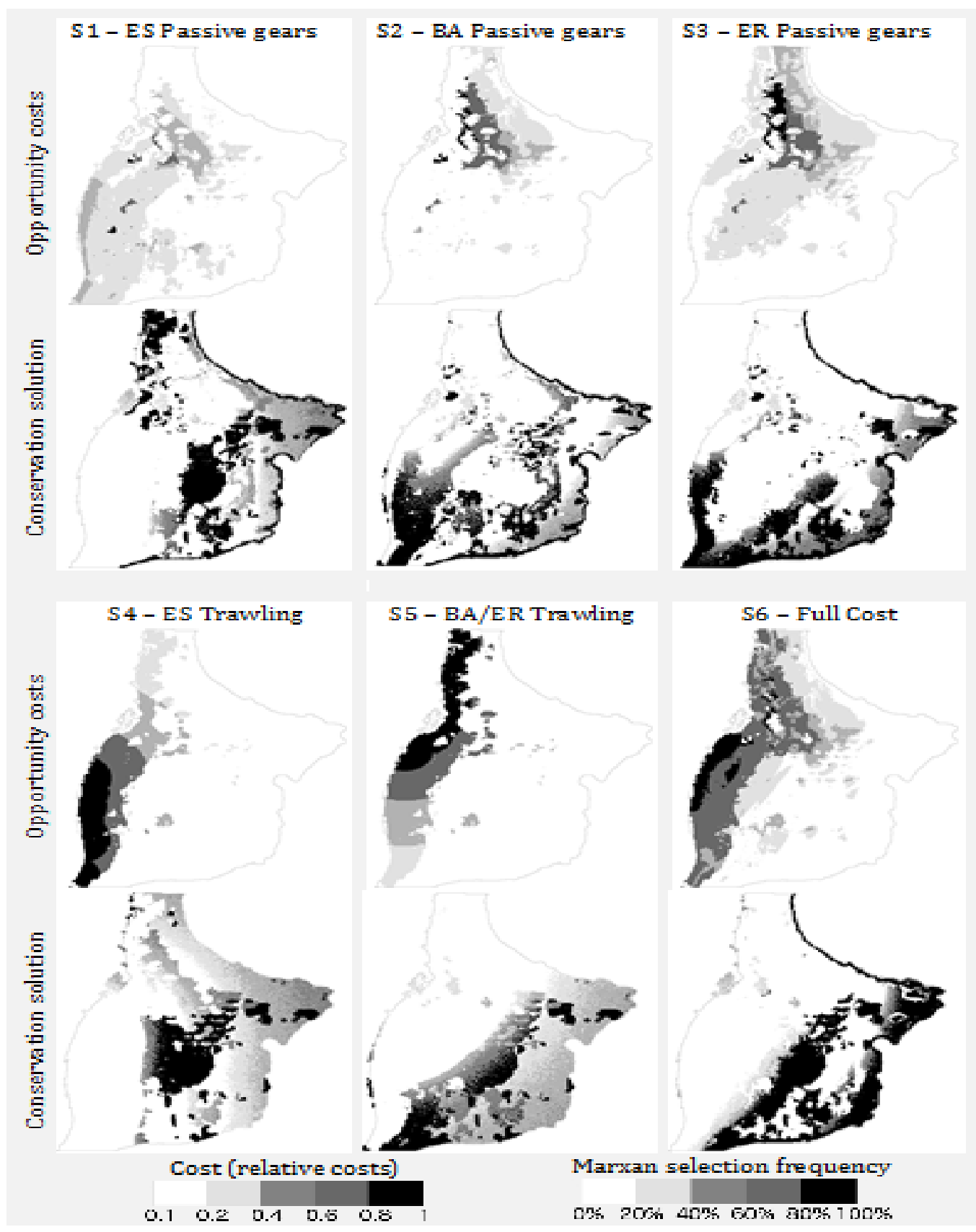

Figure 5. Multivariate analyses of opportunity cost layers (C1-C6) and Marxan selection frequencies for planning scenarios (S1-S6): (a) correlations among cost layers plotted as scatterplots with LOESS smoother (below diagonal) and corresponding Pearson's coefficients (above diagonal). (b) Multidimensional scaling plots (NMDS) of Marxan solutions with vectors representing significant model output parameters. (c) Dendrogram showing the similarity among Marxan solutions (each bar contains 100 solutions). (d) Opportunity costs of Marxan's best solution for each of the five port/vessel groups and for the "full cost" scenario.

This article is protected by copyright. All rights reserved. 


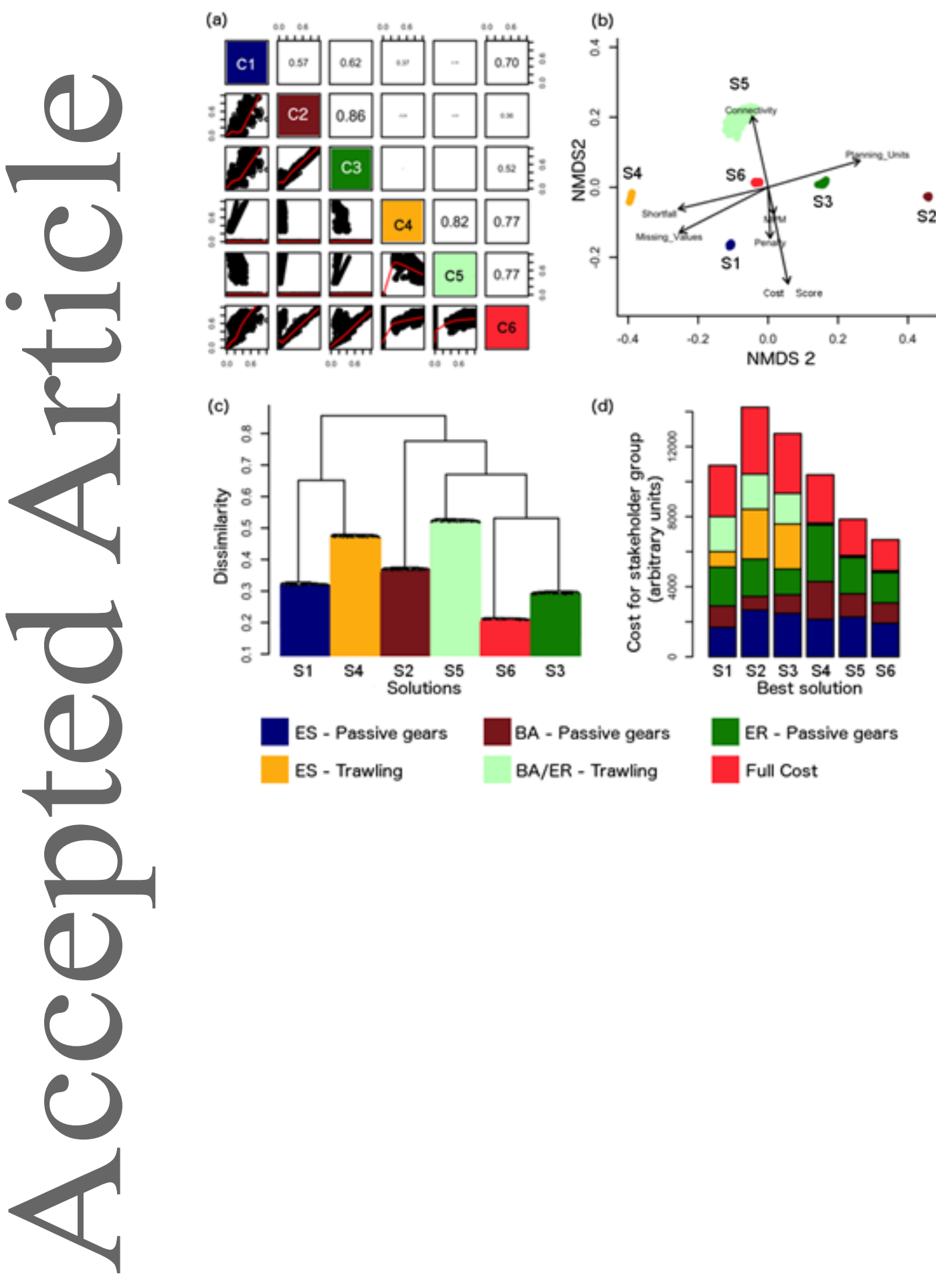

This article is protected by copyright. All rights reserved. 